\title{
Prediction of Flow Behavior during Warm Working
}

\author{
Siamak SERAJZADEH \\ Department of Materials Science and Engineering, Sharif University of Technology, P. O. Box 11365-9466, Azadi Ave., Tehran, \\ Iran. E-mail: serajzadeh@sharif.edu
}

(Received on April 27, 2004; accepted in final form on August 4, 2004)

\begin{abstract}
In this work, the effects of dynamic strain aging and dynamic recovery on metal flow during warm working are studied. Compression experiments are utilized to assess the flow behavior of a low carbon steel under warm deformation conditions. Then, a two dimensional finite element routine is coupled with dynamic recovery and dynamic strain aging models. In this way, the temperature and the velocity fields are predicted during warm working operations with regard to the effects of dynamic recovery and dynamic strain aging. Warm rolling tests are performed in order to verify the modelling results. Comparison between the predicted and measured roll forces shows reliability of the employed model.
\end{abstract}

KEY WORDS: warm rolling; dynamic strain aging; dynamic recovery; finite element analysis.

\section{Introduction}

Warm working of low carbon steels below the $\mathrm{Ar}_{3}$ temperature has been found to produce advantageous microstructures. ${ }^{1)}$ During warm working of low carbon steels, various microstructural changes such as dynamic recovery and dynamic strain aging may occur and alter the final microstructure and mechanical properties. For example, dynamic strain aging may lead to localized flow and the formation of shear bands and shear bands provide suitable sites for nucleation during subsequent recrystallization. There have been many studies on the behavior of low carbon steels during warm working. ${ }^{2-10)}$ Suitable conditions for warm working by forging and rolling have been considered by Hawkins. ${ }^{2}$ Dynamic strain aging during wire drawing and its effect on flow behavior was investigated by Taheri et $a l{ }^{3)}$ They employed an upper bound approach using spherical velocity field to analyze plastic deformation during wire drawing. The results show that dynamic strain aging may occur in the deformation zone and leads to localized flow. Flow behavior of low carbon steels at different temperatures has been studied in several works and based on torsion and compression experiments, empirical equations have been proposed to describe flow stress under warm working conditions. ${ }^{4-6)}$ The developed microstructures during warm rolling of low carbon steels have been investigated by Majta and Bator. ${ }^{7)}$ They proposed empirical relationships for estimating volume fraction of static recrystallization and ferrite grain size after warm rolling. Schmickl et $a l .{ }^{8)}$ have studied the effects of warm rolling parameters on final ferrite grain size after warm working and based on their findings an empirical equation was proposed for predicting ferrite grain size. Flow stress modelling under warm rolling conditions has been carried out by Huang et $a l .{ }^{9)}$ In this research, two grades of commercial $\mathrm{Ti}-\mathrm{Nb}$ stabilized interstitial free steels were investigated and a flow stress model with regard to dynamic recovery and recrystallization was developed to predict flow behavior of steels during warm rolling. The microstructure and recrystallization kinetics after warm rolling was studied by Liu et al. ${ }^{10)}$ They have shown that dynamic strain aging could be responsible for the formation of moderate and intense shear bands in IF and low carbon steels, respectively.

Although, there are a few works concentrating on flow behavior during warm rolling and warm forging operations. However, in these works, the metallurgical aspects of warm working and the microstructure after final annealing process were mainly taken. In this study, by means of compression experiments, dynamic strain aging phenomenon and flow behavior of a low carbon steel is studied. The velocity and the temperature fields within the steel are determined employing a two-dimensional finite element analysis with regard to the effects of dynamic recovery and dynamic strain aging. The developed model is capable of considering the effects of various process parameters such as deformation speed and reduction on the strain distribution. Warm rolling experiments are performed to verify the modelling results. The comparison between the predicted and measured rolling forces shows the validity of the model predictions.

\section{Theoretical Analysis}

During warm working, dynamic recovery may take place and affect the flow behavior. In this work, to determine the flow stress of deforming steel, the proposed model by Kocks and Mecking ${ }^{11)}$ is employed as below:

$$
d \rho / d \varepsilon=k_{1} \rho^{1 / 2}-k_{2} \rho
$$

where $\rho$ is the dislocation density, $\varepsilon$ is the plastic strain, $k_{1}$ and $k_{2}$ represent the rates of dislocation storage and recovery, respectively. Utilizing the classic relationship between 
stress and dislocation density, $\sigma=\alpha G b \rho^{0.5}$, where $\alpha$ is a material constant, $b$ is the distance between atoms in the slip direction and $G$ is the shear modulus, the variation of flow stress with respect to applied strain can be expressed as the following differential equation:

$$
\begin{gathered}
2 d \sigma / d \varepsilon=k_{1}(\alpha G b)-k_{2} \sigma . \\
\sigma=\sigma_{0} \quad \text { at } \quad \varepsilon=0
\end{gathered}
$$

In this equation, $k_{1}$ may be evaluated as $\left(\theta_{\mathrm{II}} / G\right)(\alpha b)^{-1}$ where $\theta_{\text {II }}$ may be estimated function of shear modulus. ${ }^{11)} k_{2}$ is a function of deformation conditions ${ }^{11)}$ and it can be determined through experiments. It may use Eq. (2) when the flow stress reaches the steady state conditions, $d \sigma / d \varepsilon=0$, under these circumstances, $k_{2}$ can be taken as below:

$$
k_{2}=k_{1}(\alpha G b) / \sigma_{\text {Rec }}
$$

here $\sigma_{\operatorname{Rec}}$ is the saturated flow stress due to dynamic recovery that it is assessed by the stress-strain curves. This parameter can be expressed by the following relationship. ${ }^{12)}$

$$
\sigma_{\operatorname{Rec}}=A d_{0}{ }^{\mathrm{q}} z^{m}
$$

where, $z$ is the Zener-Hollomon parameter (Eq. (5)), $d_{0}$ is the initial grain size and $A, q$ and $m$ are material constants.

$$
z=\dot{\varepsilon} \exp \left(\frac{Q_{\mathrm{def}}}{R T}\right)
$$

here $T$ is absolute temperature, $R$ is the gas constant, $\dot{\varepsilon}$ is the applied strain rate and $Q_{\text {def }}$ is the apparent activation energy for warm deformation which is calculated by the following relationship. ${ }^{12)}$

$$
Q / R=-\partial(\operatorname{Ln} \dot{\varepsilon}) /\left.(1 / T)\right|_{\sigma_{s}}
$$

Note that Eq. (2) is a nonlinear differential equation that can be solved by the aid of numerical techniques as the finite difference method. ${ }^{13)}$ In this approach, using the Taylor's expansion and difference approximation, the above ordinary differential equation may be reduced to a linear equation as below:

$$
\begin{gathered}
d \sigma / d \varepsilon=k_{1}(\alpha G b)-k_{2} \sigma=f(\sigma) \\
\sigma\left(\varepsilon_{n}\right) \cong \sigma\left(\varepsilon_{n}-\Delta \varepsilon\right)+\frac{\Delta \varepsilon}{2}\left[f_{n}(\sigma)+f_{n-1}(\sigma)\right]
\end{gathered}
$$

where $\Delta \varepsilon$ is the strain increment and $\sigma\left(\varepsilon_{n}\right), \sigma\left(\varepsilon_{n}-\Delta \varepsilon\right)$ are flow stress at the steps of $n$th and $(n-1)$ th, respectively. To calculate the flow stress at each strain an iterative procedure should be adopted because of the implicit form of the above equation. It should be noted that for the event of serrated flow, dynamic recovery could not occur because of mobile dislocations are locked by interstitial alloy elements. Under this condition, "power-law" equation is employed as following $^{2)}$ :

$$
\sigma=B \dot{\varepsilon}^{m} \varepsilon^{n}
$$

where $\sigma$ is the instantaneous flow stress of metal, $\varepsilon$ and $\dot{\varepsilon}$ are true strain and true strain rate, respectively, $B$ is a temperature dependent coefficient. $n$ and $m$ are work hardening and strain rate sensitivity factors, respectively. Also, to determine the region of serrated flow the Arrhenius-type equation has been used as follows:

$$
\dot{\varepsilon}=A \exp (-Q / R T)
$$

here $R$ and $A$ are the gas constant and frequency factor, respectively and $Q$ is the activation energy.

In order for evaluating the deformation conditions at each time step a finite element analysis is coupled with dynamic strain aging and dynamic recovery models. In this method, the basic idea is minimization of energy functional on descritized deforming body. ${ }^{14,15)}$ The principle equations for determining temperature and velocity fields can be described as following:

$$
\begin{gathered}
\int W_{i}\left(\nabla(k(T) \nabla T)+\dot{q}-\rho_{\mathrm{w}} c \frac{\partial T}{\partial t}\right) d V=0 \ldots \ldots . .(10 . \\
\int \bar{\sigma} \delta \dot{\bar{\varepsilon}} d V+\int K \dot{\varepsilon}_{\mathrm{v}} \delta \dot{\varepsilon}_{\mathrm{v}} d V-\int F_{i} \delta u_{i} d s=0 \ldots \ldots \ldots
\end{gathered}
$$

where $\rho_{\mathrm{w}}, c$ and $k$ are density, specific heat, and thermal conductivity of the deforming steel, respectively. $\dot{q}$ expresses the volumetric rate of heat of deformation. $\bar{\sigma}$ is instantaneous flow stress which is calculated employing the mentioned approach and $\dot{\bar{\varepsilon}}$ is effective strain rate, $W_{i}$ is weighting function and $K$ is an arbitrary large positive number. In this work, the warm rolling of strip is considered and the deformation and the heat transfer equations can be assumed as two-dimensional problems. ${ }^{16)}$ The thermal boundary conditions utilized in the model for the heat transfer equation are:

$$
\begin{aligned}
& -k \frac{\partial T}{\partial n}=h_{\text {con }}\left(T-T_{\mathrm{R}}\right)-q_{\text {fric }} \\
& -k \frac{\partial T}{\partial n}=h_{\infty}\left(T-T_{\infty}\right) \ldots \ldots \ldots \ldots
\end{aligned}
$$

here $T_{\mathrm{R}}$ is the work-roll surface temperature that should be simultaneously determined by another finite element analysis. ${ }^{17)} T_{\infty}$ is surrounding temperatures and $h_{\text {con }}$ is the interface heat transfer coefficient and for the other regions the dominated heat transfer mechanism is convection. $q_{\text {fric }}$ is the distributed surface flux generated from frictional sliding. ${ }^{17)}$ To describe the boundary condition for plastic deformation equation, the following equation was employed for describing frictional stress at contact area with workrolls. ${ }^{18)}$

$$
\sigma_{\mathrm{f}}=k_{\mathrm{s}} m\left\{-\frac{2}{\pi} \tan ^{-1}\left(\frac{v_{\mathrm{r}}}{a}\right)\right\}
$$

where $k_{\mathrm{s}}$ is the shear yield stress, $v_{\mathrm{r}}$ the relative velocity between the tool and the deforming metal, $m$ the friction factor, and $a$ is a positive constant of the order of $10^{-4}$.

Equations (2), (10) and (11) should be solved simultaneously to have the temperature distribution, the velocity field and the kinetics of dynamic recovery. In order to solve the heat conduction and the energy equations, a two dimensional finite element analysis utilizing four-node isoparametric elements ${ }^{19)}$ are employed and Newton-Raphson and direct iteration methods are used to solve the nonlinear system of 


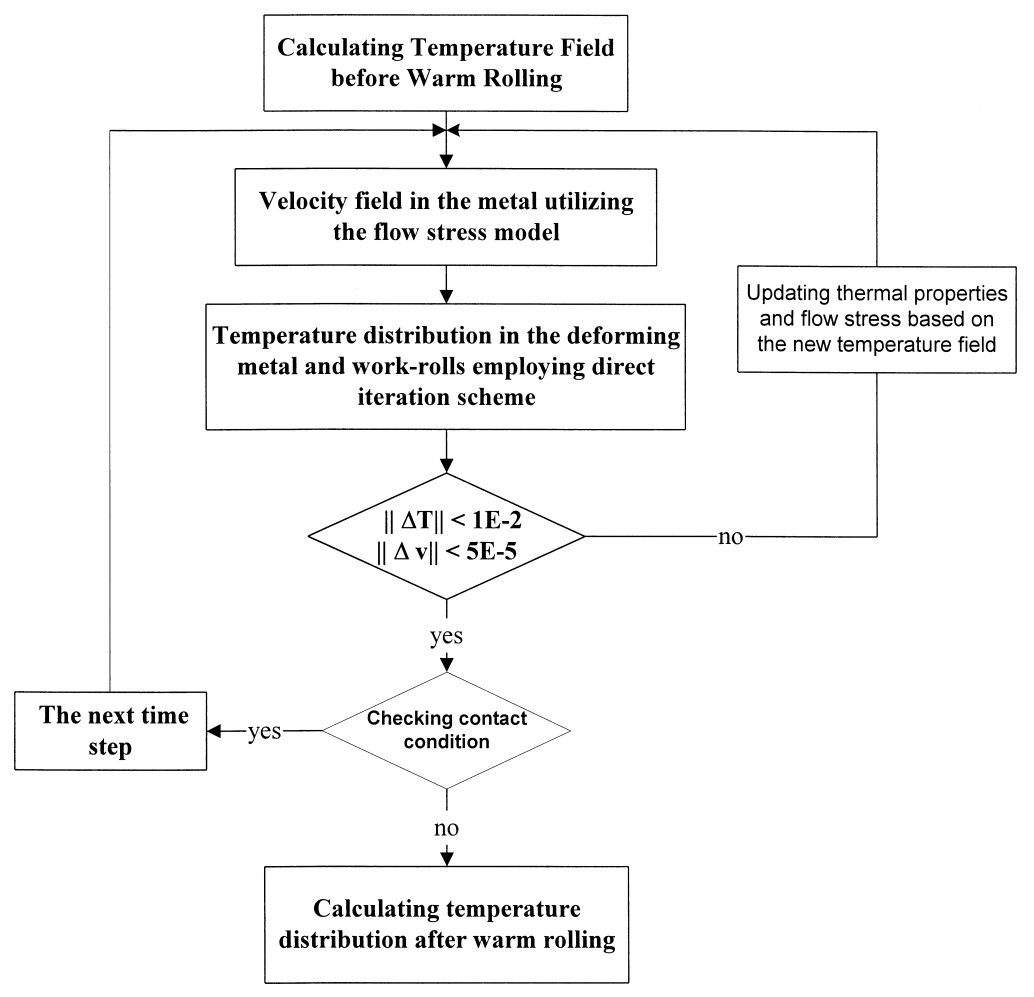

Fig. 1. Flow chart of the employed algorithm.

Table 1. Chemical composition of the steel employed in this study (mass $\%)$.

\begin{tabular}{|c|c|c|c|c|c|c|c|}
\hline $\mathrm{C}$ & $\mathrm{Mn}$ & $\mathrm{Si}$ & $\mathrm{P}$ & $\mathrm{S}$ & $\mathrm{Cr}$ & $\mathrm{Nb}$ & $\mathrm{N}$ \\
\hline 0.05 & 0.40 & 0.04 & 0.06 & 0.02 & 0.05 & - & 0.003 \\
\hline
\end{tabular}

resulting equations. ${ }^{14)}$ The employed algorithm is given as a flow chart in Fig. 1.

\section{Experimental}

A low carbon steel with the chemical composition given in Table 1 was considered and compression experiments were carried out to study flow behavior of the steel. The samples were machined out of the as received hot rolled bars with the deformation axis parallel to pervious hot rolling direction and a height to diameter ratio of 1.5 was chosen for the samples. Then, compression experiments were conducted to achieve the stress-strain curves. These experiments were performed at the temperatures in the range of 100 to $800^{\circ} \mathrm{C}$ and the mean strain rates of $10^{-2}$, $10^{-1}$ and $1\left(\mathrm{~s}^{-1}\right)$. The experiments were carried out on a computerized servo-hydraulic MTS machine. All samples were heated to $900^{\circ} \mathrm{C}$ and held for $15 \mathrm{~min}$ at this temperature and then rapidly cooled to the deformation temperature at which it was held for 5 min to eliminate the thermal gradient before deformation. To eliminate frictional stress Teflon pieces were utilized at the interface of tools and samples. Figure 2 shows the employed heating and cooling program and Fig. 3 displays typical stress-strain curves obtained from compression experiments. It is seen that the

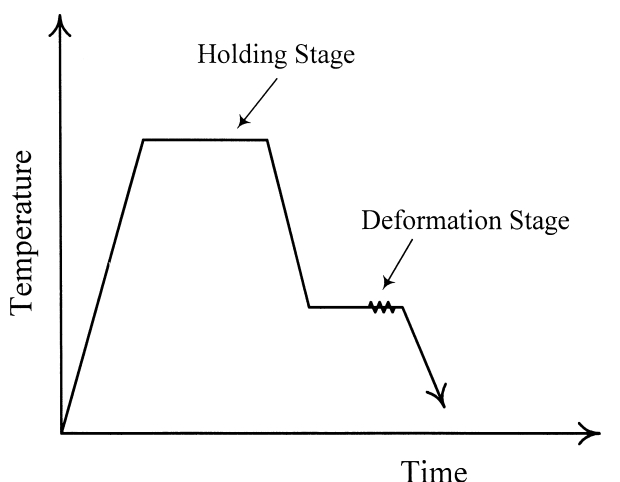

Fig. 2. The heating program used in compression experiments.

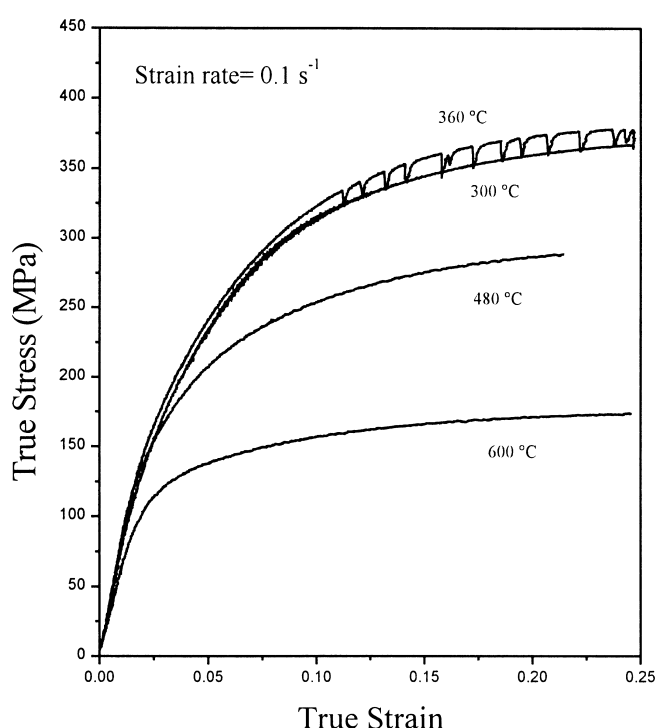

Fig. 3. Typical stress-strain curves obtained from compression experiments. 
Table 2. The deformation condition used for warm rolling experiments.

\begin{tabular}{|c|c|c|}
\hline Temperature, ${ }^{\circ} \mathrm{C}$ & Reduction, \% & Rolling Speed, rpm \\
\hline 600 & 14 & 42.5 \\
\hline 650 & 23 & 62 \\
\hline 700 & 30 & 82 \\
\hline
\end{tabular}

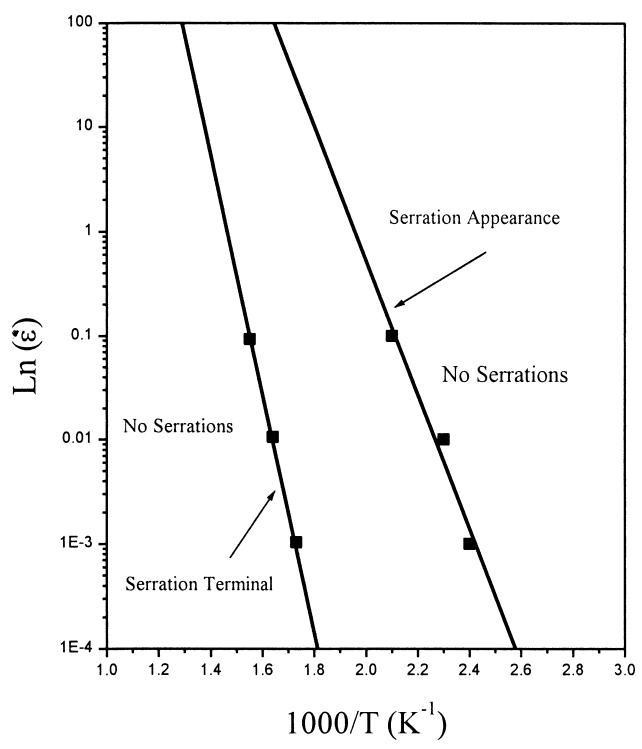

Fig. 4. (a) Serrated flow under different deformation conditions, (b) Serration yielding region based on applied temperature and strain rate.

serrated flow occurs under different working conditions. It is worth noting that for the case of testing at high strain rates (i.e. $\dot{\varepsilon} \geq 1$ ), the stress-strain curves were corrected by the procedure mentioned in Ref. 20).

In addition, for verifying the modelling results, warm rolling tests were carried out at different rolling speeds and reductions and the roll force was measured. Dimensions of the samples used for the warm rolling tests were $3 \times 50 \times 100$ (in $\mathrm{mm}$ ) and the work-roll diameter was $150 \mathrm{~mm}$. The deformation parameters used in the warm rolling experiments are listed in Table 2.

\section{Results and Discussion}

The results show that the steel shows serrated flow at temperatures between 120 to $450^{\circ} \mathrm{C}$ for the employed strain rates in compression experiments. As well, the activation energy for appearance of serrated yielding was calculated as $86(\mathrm{~kJ} / \mathrm{mol})$ and the activation energy for termination of serration was determined as $158(\mathrm{~kJ} / \mathrm{mol})$, which are in agreement with those calculated in other works. ${ }^{3,21)}$ Figure 4 shows the conditions that serrated flow occurs, respectively. In addition, the strain rate sensitivity was calculated using the flow stress at the true strain of 0.15 . The dependence of strain rate sensitivity on temperature was determined by calculating this parameter at different temperatures. Figure 5 shows the variation of strain rate sensitivity $v s$. temperature. There is a region with negative strain rate sensitivity indicating the happening of dynamic strain

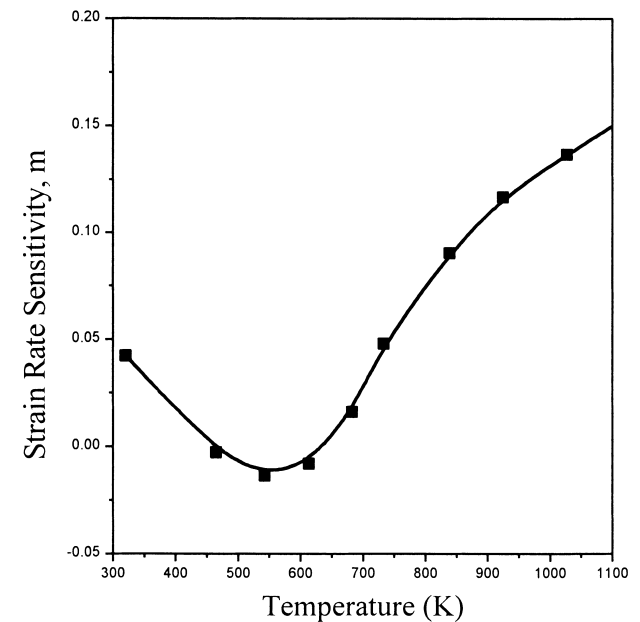

Fig. 5. Variation of strain rate sensitivity $v s$. temperature.

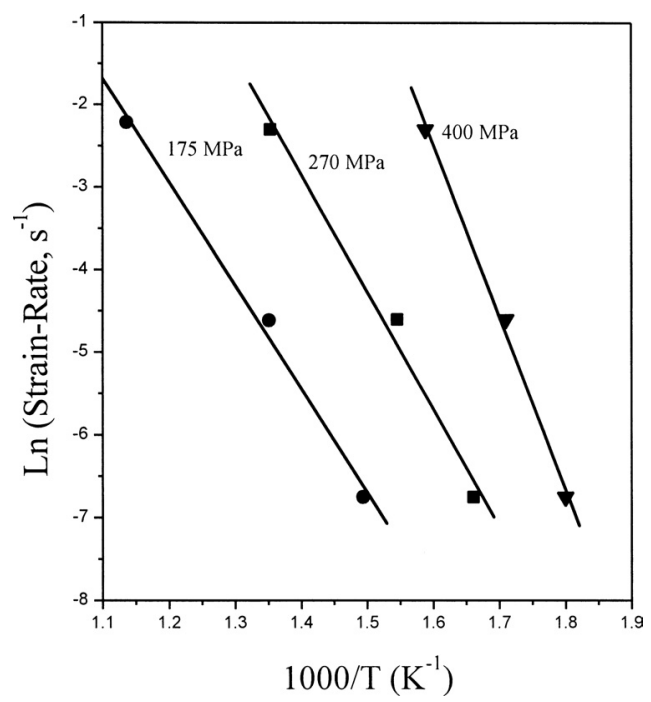

Fig. 6. Ln $(\dot{\varepsilon})$ vs. $1 / T$ curves at various steady state stresses.

aging. For the no-serration regions, the mean apparent activation energy for warm deformation is calculated as 275 $\mathrm{kJ} / \mathrm{mol}$ (Fig. 6) that is close to the self-diffusion energy in ferrite $(239 \mathrm{~kJ} / \mathrm{mol}){ }^{22)}$

Figure 7 shows the predicted and measured roll forces for the warm rolling operations at different reductions and rolling speeds. There is a good consistency between the two types of data that confirms the utilized model. It should be noted that the difference between the experimental and theoretical results can be attributed to the employed thermophysical properties particularly the utilized interface heat transfer coefficient. Figures 8 shows the predicted mesh distortion and temperature distribution during warm rolling. It is observed that the severe temperature variation is limited to a narrow region. Figure 9 displays the strain distribution along thickness direction for various points of deformation zone and Fig. 10 shows the variation of strain rate along deformation zone. The predictions show that at low to moderate rolling speeds (15 to $45 \mathrm{rpm}$ ) dynamic strain aging may occur mainly at near surface region as illustrated in Fig. 10 and strain accumulation phenomenon can be developed at sub-surface regions (Fig. 9). It may be attributed to effect of dynamic strain aging and resulting negative strain rate sensitivity. It should be noted that the same behavior has been reported for the case of wire drawing of 


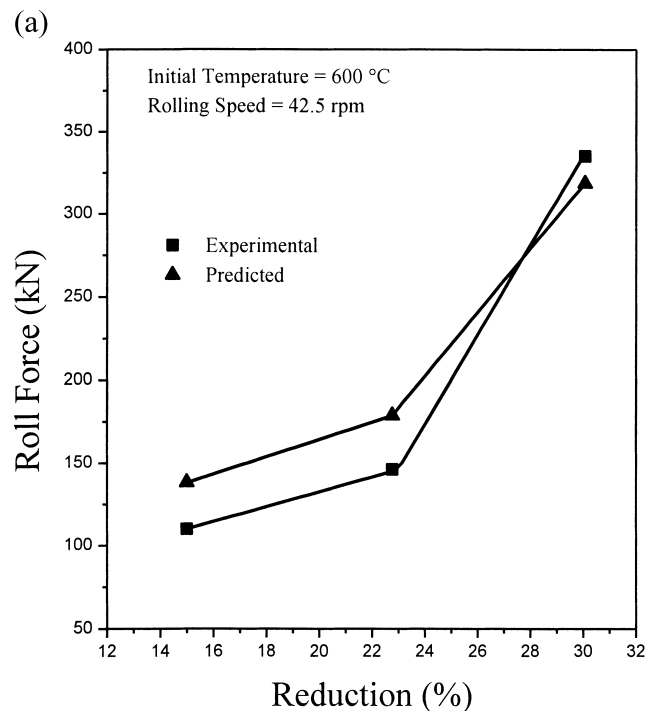

(b)

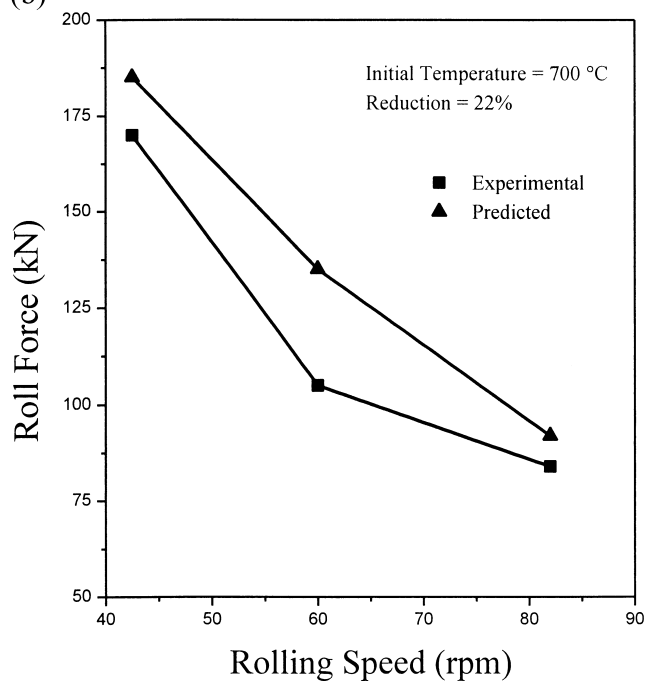

Fig. 7. Comparison between the predicted and measured roll forces.

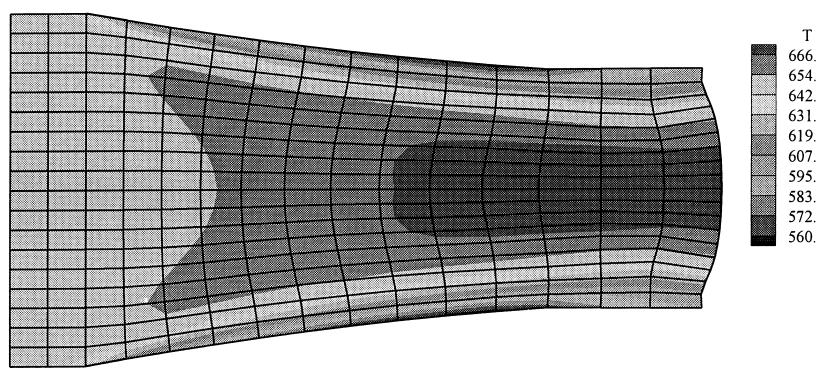

Fig. 8. Finite element mesh distortion after warm rolling. Initial temperature $=700^{\circ} \mathrm{C}$, rolling speed $=25 \mathrm{rpm}$, reduction $=$ $30 \%$

low carbon steels. ${ }^{3)}$ It is worth noting that occurrence of dynamic strain aging is dependent on the rate of heat transfer to the work rolls. At low rolling speeds i.e. rolling speeds less than $25 \mathrm{rpm}$ or higher interface heat transfer coefficient $\left(h_{\text {con }}\right)$, temperature drop in the strip is increased ${ }^{23)}$ and serrated flow occurs at low strain rates as shown in Fig. 4. In this condition, dynamic strain aging is possible to occur at the surface of strip. While at higher rolling speeds, severe temperature drop is limited to the surface of strip as illustrated in Fig. 11 and serrated flow may happen in deeper re-

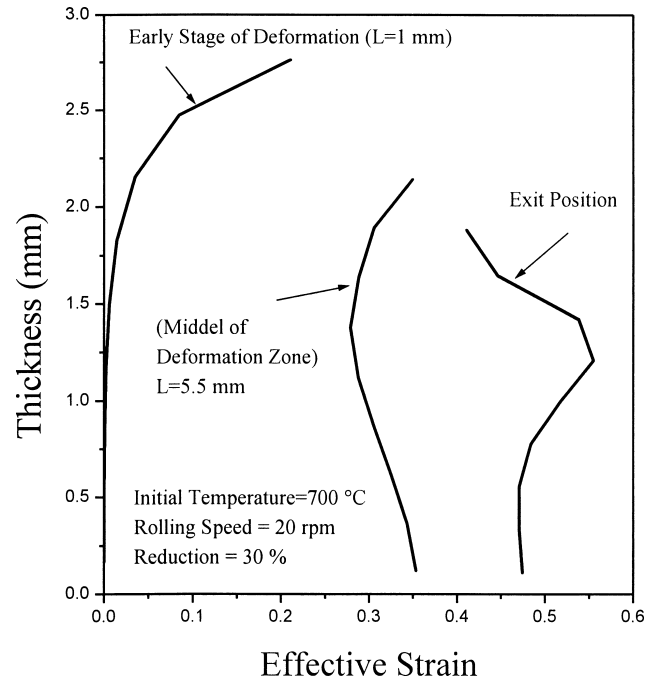

Fig. 9. Effective strain variation along thickness direction after warm rolling.

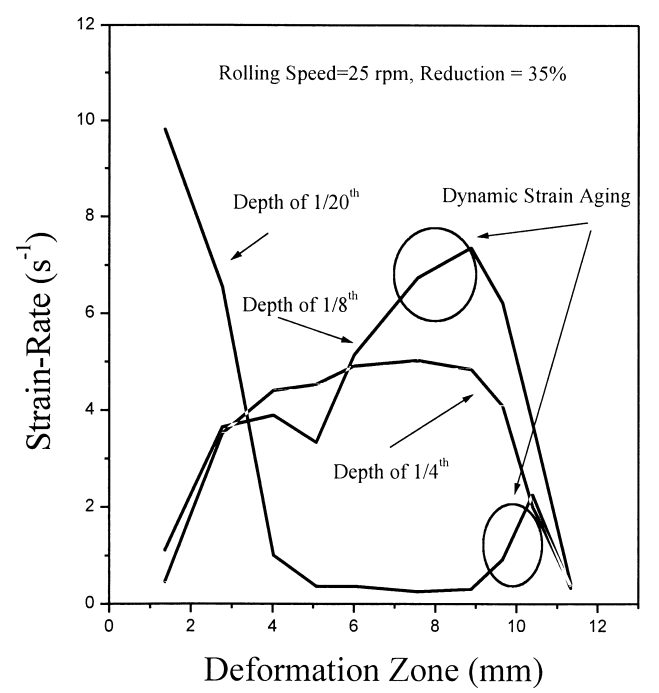

Fig. 10. Variation of effective strain rate along deformation zone.

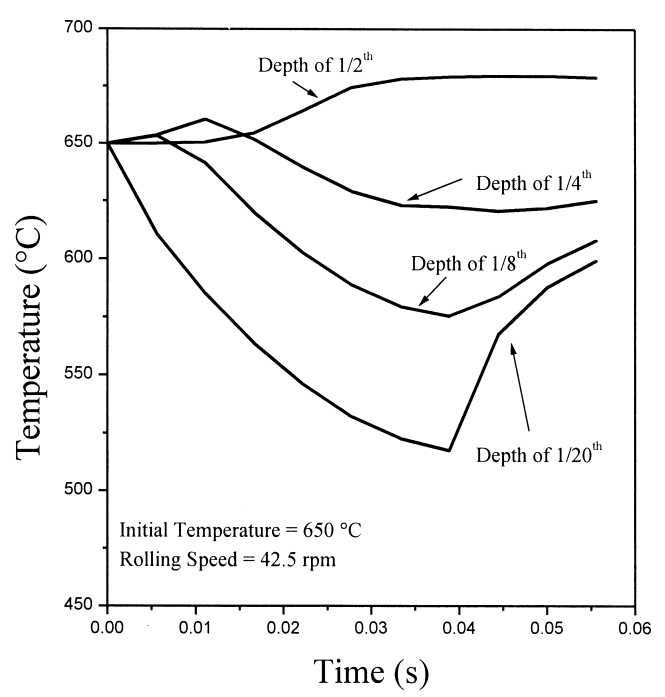

Fig. 11. Temperature variation at different points of strip during warm rolling. 
(a)

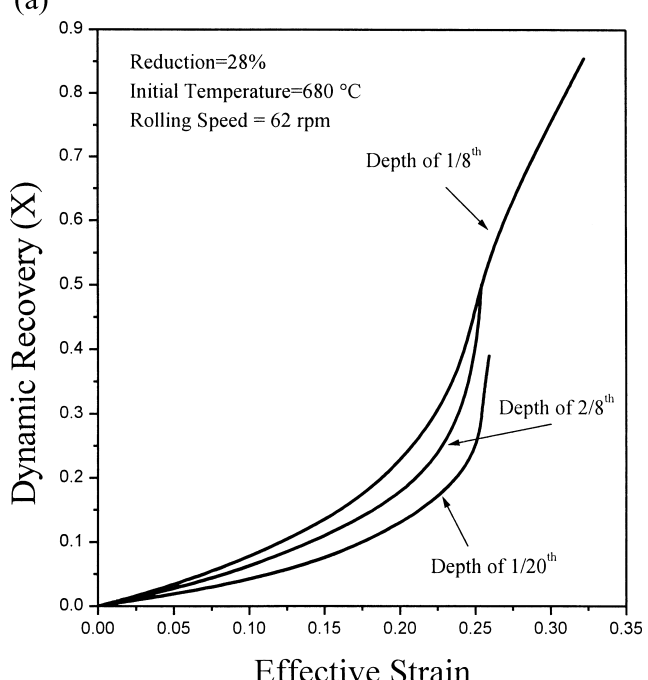

(b)

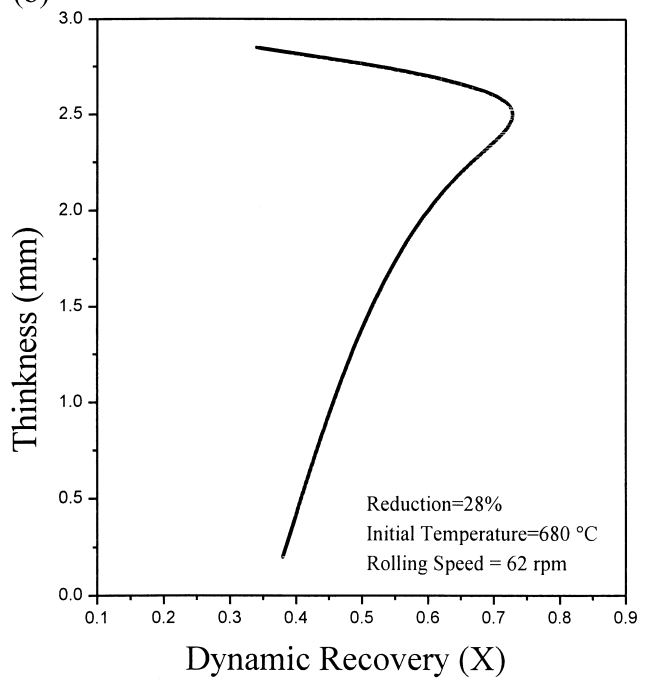

Fig. 12. (a) Progress of dynamic recovery during warm rolling at different points of deforming steel, (b) distribution of dynamic recovery progress at the end of deformation zone.

gions where the temperature drop is not severe and strain rate is high enough to occur dynamic strain aging (Fig. 10).

Dynamic recovery may also affect the velocity and strain distributions. The difference in the kinetics of dynamic recovery at various points of deforming steel affects strain distribution and may lead to formation of localized flow. For example in warm rolling at high temperatures and strain rates, where the dynamic recovery is the dominant mechanism, sub-surface layers which tolerate more shear strains are suitable sites for dynamic recovery to occur. Figures 12(a) and 12(b) show the progress of dynamic recovery along deformation zone in various regions and distribution of dynamic recovery progress at the exit point of deformation zone, respectively. It should be noted that for calculating the progress of dynamic recovery the following equation has been utilized.

$$
X=\frac{\sigma-\sigma_{0}}{\sigma_{\mathrm{p}}-\sigma_{0}}
$$

here $\sigma_{0}$ is the yield stress. It is seen that in the sub-surface regions the kinetics of dynamic recovery is higher in com-

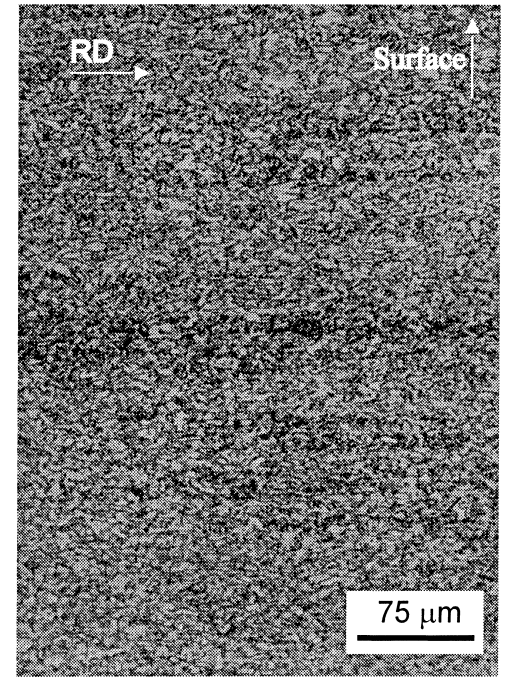

Fig. 13. Optical micrograph of a sampled rolled at rolling speed of $62 \mathrm{rpm}$.

parison with the other regions. The faster kinetics of dynamic recovery causes more flow softening and may contribute to formation of localized flow. Microstructural examination shows the same behavior, for example, Fig. 13 illustrates the optical microghraph of a sample rolled with initial temperature of $680^{\circ} \mathrm{C}$, reduction of $28 \%$ and rolling speed of $62 \mathrm{rpm}$. As it is predicted, localized flow can be observed at the sub-surface region. It is worth noting that a similar effect has been reported by the others. ${ }^{24)}$

\section{Conclusions}

In this study, a mathematical model is developed to assess the temperature and the velocity fields during warm working of a low carbon steel. The model considers the effects of dynamic recovery and dynamic strain aging on flow behavior. For doing so, the Kocks-Mecking model and "power-law" equation are coupled with plastic deformation and heat conduction models. Warm rolling experiments were performed to verify the predictions. Comparison between the measured and predicted roll forces shows the reliability of the modelling results. The predictions show that both dynamic strain aging and dynamic recovery may occur and contribute to the development of accumulation in plastic strain.

\section{REFERENCES}

1) J. M. Robinson and M. P. Shaw: Int. Mater. Rev., 39 (1994), 113.

2) D. N. Hawkins: J. Mech. Work. Technol., 11 (1985), 5.

3) A. Karimi Taheri, T. M. Maccagno and J. Jonas: ISIJ Int., 35 (1995), 1532 .

4) A. Niechajowicz and A. Tobota: J. Mater. Process. Technol., 106 (2000) 123.

5) C. Gupta, J. K. Chakavartty, S. L. Wadekar and J. S. Dubey: Mater. Sci. Eng. A, 292A (2000), 49.

6) L. Xinbo, Z. Fubao, F. Jianhua and Z. Zhiliang: J. Mater. Process Technol., 122 (2002) 38.

7) J. Majta and A. Bator: Metal Forming '2000, ed. By Pietrzyk, Balkema, Rotterdom, (2000), 461.

8) A. Schmickel, D. Yu, C. Killmore, D. Langley and T. Chandra: ISIJ Int., 36 (1996), 1279.

9) C. Huang, E. B. Hawbolt, X. Chen, T. R. Meadowcroft and D. J. Matlock: Acta Mater, 49 (2001), 1445.

10) D. Liu, M. R. Toroghinezhad and J. Jonas: ISIJ Int., 42 (2002), 751. 
11) Y. Estrin and H. Mecking: Acta Metall., 32 (1984), 57.

12) S. B. Davenport, N. J. Silk, C. N. Sparks and C. M. Sellars: Mater Sci. Technol., 16 (2000), 539.

13) R. K. Livesly: Mathematical Methods for Engineers, Ellis Horwood Limited, Chichester, England, (1989), 231.

14) H. S. Carslaw and J. C. Jaeger: Conduction of Heat in Solids', Oxford University Press, Oxford, (1959), 51.

15) S. Kobayashi, S. I. Oh and T. Altan Metal Forming and Finite Element Method, Oxford University Press, Oxford, (1988), 83

16) S. M. Hwang, M. S. Joun and Y. H. Kang: Trans. ASME J. for Ind., 115 (1993), 290.

17) S. Serajzadeh and F. Mucciardi: Modelling and Simulation in Mater. Sci. Eng., 11 (2003), 179.
18) S. I. Oh: Int. J. Mech. Sci., 24 (1982), 479.

19) F. L. Stasa: Applied Finite Element Method, CBS Publishing Ltd., Japan, (1985), 371

20) A. Laasraoui and J. J. Jonas: Metall. Trans. A, 22A (1990), 1545.

21) K. G. Samuel, S. L. Mannan and P. Rodriguez: Acta Metall., 36 (1988) 2323.

22) P. Shewmon: Diffusion in Solids, 2nd ed., TMS, Warrendale, PA, (1989).

23) A. N. Karagiozis and J. G. Lenard: Trans. ASME J. Eng. Mater. and Tech., 110 (1988), 17.

24) L. Xinbo, X. Hongsheng and Z. Zhiliang: J. Mater. Proc. Technol., 139 (2003), 543. 